CUBO A Mathematical Journal Vol.16, Noㅡ, (01-10). October 2014

\title{
On upper and lower $\omega$-irresolute multifunctions
}

\author{
C. Carpintero \\ Department of Mathematics, \\ Universidad De Oriente, \\ Nucleo De Sucre Cumana, Venezuela. \\ Facultad de Ciencias Basicas, \\ Universidad del Atlantico, Colombia. \\ carpintero.carlos@gmail.com \\ N. RAJESH \\ Department of Mathematics, \\ Rajah Serfoji Govt. College, \\ Thanjavur-613005, \\ Tamilnadu, India. \\ nrajesh_topology@yahoo.co.in
}

\author{
E. RosAs \\ Department of Mathematics, \\ Universidad De Oriente, \\ Nucleo De Sucre Cumana, Venezuela. \\ Facultad de Ciencias Basicas, \\ Universidad del Atlantico, Colombia. \\ ennisrafael@gmail.com \\ S. SARANYASRI \\ Department of Mathematics, \\ M. R. K. Institute of Technology, \\ Kattumannarkoil, Cuddalore -608 301, \\ Tamilnadu, India. \\ srisaranya_2010@yahoo.com
}

\begin{abstract}
In this paper we define upper (lower) $\omega$-irresolute multifunction and obtain some characterizations and some basic properties of such a multifunction.

\section{RESUMEN}

En este artículo definimos la multifunción superior (inferior) $\omega$-irresoluto y obtenemos algunas caracterizaciones y algunas propiedades básicas de este tipo de multifunciones.
\end{abstract}

Keywords and Phrases: $\omega$-open set, $\omega$-continuous multifunctions, $\omega$-irresolute multifunctions.

2010 AMS Mathematics Subject Classification: 54C05, 54C601, 54C08, 54C10 


\section{Introduction}

It is well known that various types of functions play a significant role in the theory of classical point set topology. A great number of papers dealing with such functions have appeared, and a good number of them have been extended to the setting of multifunctions: [4], [5], [6], [7], [10, [11, [12, , 13, , 15]. This implies that both, functions and multifunctions are important tools for studying other properties of spaces and for constructing new spaces from previously existing ones. Recently, Zorlutuna introduced the concept of $\omega$-continuous multifunctions [15], $\omega$-continuity which is a weaker form of continuity in ordinary was extended to multifunctions. The purpose of this paper is to define upper (respectively lower) $\omega$-irresolute multifunctions and to obtain several characterizations of such a multifunction.

\section{Preliminaries}

Throughout this paper, $(X, \tau)$ and $(Y, \sigma)$ (or simply $X$ and $Y$ ) always mean topological spaces in which no separation axioms are assumed unless explicitly stated. Let $A$ be a subset of a space $X$. For a subset $A$ of $(X, \tau), \operatorname{Cl}(A)$ and $\operatorname{int}(A)$ denote the closure of $A$ with respect to $\tau$ and the interior of $A$ with respect to $\tau$, respectively. Recently, as generalization of closed sets, the notion of $\omega$-closed sets were introduced and studied by Hdeib $[9$. A point $x \in X$ is called a condensation point of $A$ if for each $U \in \tau$ with $x \in U$, the set $U \cap A$ is uncountable. $A$ is said to be $\omega$-closed [9] if it contains all its condensation points. The complement of an $\omega$-closed set is said to be $\omega$-open. It is well known that a subset $W$ of a space $(X, \tau)$ is $\omega$-open if and only if for each $x \in W$, there exists $\mathrm{U} \in \tau$ such that $\chi \in \mathcal{U}$ and $\mathbf{U} \backslash W$ is countable. The family of all $\boldsymbol{\omega}$-open subsets of a topological space $(X, \tau)$ is denoted by $\omega \mathrm{O}(X)$, forms a topology on $X$ finer than $\tau$. The family of all $\omega$-closed subsets of a topological space $(X, \tau)$ is denoted by $\omega C(X)$. The $\omega$-closure and the $\omega$-interior, that can be defined in the same way as $\operatorname{Cl}(A)$ and $\operatorname{int}(A)$, respectively, will be denoted by $\omega \operatorname{Cl}(A)$ and $\omega \operatorname{int}(A)$, respectively. We set $\omega \mathrm{O}(X, x)=\{A: A \in \omega O(X)$ and $x \in A\}$. A subset $\mathrm{U}$ of $\mathrm{X}$ is called an $\omega$-neighborhood of a point $x \in X$ if there exists $\mathrm{V} \in \omega \mathrm{O}(X, x)$ such that $\mathrm{V} \subset \mathrm{U}$. By a multifunction $F:(X, \tau) \rightarrow(Y, \sigma)$, following [3], we shall denote the upper and lower inverse of a set $B$ of $Y$ by $F^{+}(B)$ and $F^{-}(B)$, respectively, that is, $F^{+}(B)=\{x \in X: F(x) \subset B\}$ and $F^{-}(B)=$ $\{x \in X: F(x) \cap B \neq \emptyset\}$. In particular, $F^{-}(Y)=\{x \in X: y \in F(x)\}$ for each point $y \in Y$ and for each $A \subset X, F(A)=\bigcup_{x \in A} F(x)$. Then $F$ is said to be surjection if $F(x)=y$.

Definition 2.1. A multifunction $\mathrm{F}:(\mathrm{X}, \tau) \rightarrow(\mathrm{Y}, \sigma)$ is said to be:

(i) upper $\boldsymbol{\omega}$-continuous (briefly u.w-c.) [15] if for each point $\mathrm{x} \in \mathrm{X}$ and each open set $\mathrm{V}$ containing $\mathrm{F}(\mathrm{x})$, there exists $\mathrm{U} \in \omega \mathrm{O}(\mathrm{X}, \mathrm{x})$ such that $\mathrm{F}(\mathrm{U}) \subset \mathrm{V}$;

(ii) lower $\omega$-continuous (briefly l.w-c.) [15] if for each point $\chi \in X$ and each open set $\mathrm{V}$ such that $\mathrm{F}(\mathrm{x}) \cap \mathrm{V} \neq \emptyset$, there exists $\mathrm{U} \in \omega \mathrm{O}(\mathrm{X}, \mathrm{x})$ such that $\mathrm{U} \subset \mathrm{F}^{-}(\mathrm{V})$. 


\section{On upper and lower $\omega$-irresolute multifunctions}

Definition 3.1. A multifunction $\mathrm{F}:(\mathrm{X}, \tau) \rightarrow(\mathrm{Y}, \sigma)$ is said to be:

(i) upper $\omega$-irresolute (briefly $\mathrm{u} . \omega$-i.) if for each point $\mathrm{x} \in \mathrm{X}$ and each $\boldsymbol{\omega}$-open set $\mathrm{V}$ containing $\mathrm{F}(\mathrm{x})$, there exists $\mathrm{U} \in \omega \mathrm{O}(\mathrm{X}, \mathrm{x})$ such that $\mathrm{F}(\mathrm{U}) \subset \mathrm{V}$;

(ii) lower $\omega$-irresolute (briefly l.w-i.) if for each point $\mathrm{x} \in \mathrm{X}$ and each $\boldsymbol{\omega}$-open set $\mathrm{V}$ such that $\mathrm{F}(\mathrm{x}) \cap \mathrm{V} \neq \emptyset$, there exists $\mathrm{U} \in \omega \mathrm{O}(\mathrm{X}, \mathrm{x})$ such that $\mathrm{U} \subset \mathrm{F}^{-}(\mathrm{V})$.

It is clear that every upper (lower) $\omega$-irresolute multifunction is upper (lower) $\omega$-continuous. But the converse is not true as shown by the following example.

Example 3.2. Let $\mathrm{X}=\mathbb{R}$ with the topology $\tau=\{\emptyset, \mathbb{R}, \mathbb{Q}\}$. Define a multifunction $\mathrm{F}:(\mathbb{R}, \tau) \rightarrow(\mathbb{R}, \tau)$ as follows:

$$
\mathrm{F}(x)=\left\{\begin{array}{cc}
\mathbb{Q} & \text { if } x \in \mathbb{R}-\mathbb{Q} \\
\mathbb{R}-\mathbb{Q} & \text { if } x \in \mathbb{Q} .
\end{array}\right.
$$

Then $\mathrm{F}$ is u.w-c. but is not u.w-i.

In a similar form, we can find a multifunction $\mathrm{G}$ that is l.w-c. but is not l.w-i.

Theorem 3.3. The following statements are equivalent for a multifunction $\mathrm{F}:(X, \tau) \rightarrow(\mathrm{Y}, \sigma)$ :

(i) F is u.w-i.;

(ii) for each point $\mathrm{x}$ of $\mathrm{X}$ and each $\mathrm{\omega}$-neighborhood $\mathrm{V}$ of $\mathrm{F}(\mathrm{x}), \mathrm{F}^{+}(\mathrm{V})$ is an $\mathrm{\omega}$-neighborhood of $\mathrm{x}$;

(iii) for each point $\mathrm{x}$ of $\mathrm{X}$ and each $\mathrm{\omega}$-neighborhood $\mathrm{V}$ of $\mathrm{F}(\mathrm{x})$, there exists an $\mathrm{\omega}$-neighborhood $\mathrm{U}$ of $\mathrm{x}$ such that $\mathrm{F}(\mathrm{U}) \subset \mathrm{V}$;

(iv) $\mathrm{F}^{+}(\mathrm{V}) \in \omega \mathrm{O}(\mathrm{X})$ for every $\mathrm{V} \in \omega \mathrm{O}(\mathrm{Y})$;

(v) $\mathrm{F}^{-}(\mathrm{V}) \in \omega \mathrm{C}(\mathrm{X})$ for every $\mathrm{V} \in \omega \mathrm{C}(\mathrm{Y})$;

(vi) $\omega \mathrm{Cl}\left(\mathrm{F}^{-}(\mathrm{B})\right) \subset \mathrm{F}^{-}(\omega \mathrm{Cl}(\mathrm{B}))$ for every subset $\mathrm{B}$ of $\mathrm{Y}$.

Proof. $(i) \Rightarrow(i i)$ : Let $x \in X$ and $W$ be an $\omega$-neighborhood of $F(x)$. There exists $V \in \omega O(Y)$ such that $F(x) \subset V \subset W$. Since $F$ is $u . \omega$-i., there exists $U \in \omega O(X, x)$ such that $F(U) \subset V$. Therefore, we have $x \in U \subset F^{+}(V) \subset F^{+}(W)$; hence $F^{+}(W)$ is an $\omega$-neighborhood of $x$.

(ii) $\Rightarrow$ (iii): Let $x \in X$ and $V$ be an $\omega$-neighborhood of $F(x)$. Put $U=F^{+}(V)$. Then, by (ii), $U$ is an $\omega$-neighborhood of $x$ and $F(U) \subset V$.

$(\mathrm{iii}) \Rightarrow(\mathrm{i} v)$ : Let $\mathrm{V} \in \omega \mathrm{O}(\mathrm{Y})$ and $x \in \mathrm{F}^{+}(\mathrm{V})$. There exists an $\omega$-neighborhood $\mathrm{G}$ of $x$ such that $\mathrm{F}(\mathrm{G}) \subset \mathrm{V}$. Therefore, for some $\mathrm{U} \in \omega \mathrm{O}(\mathrm{X}, \mathrm{x})$ such that $\mathrm{U} \subset \mathrm{G}$ and $\mathrm{F}(\mathrm{U}) \subset \mathrm{V}$. Therefore, we obtain $x \in \mathrm{U} \subset \mathrm{F}^{+}(\mathrm{V})$; hence $\mathrm{F}^{+}(\mathrm{V}) \in \omega \mathrm{O}(\mathrm{Y})$.

$(i v) \Rightarrow(v)$ : Let $K$ be an $\omega$-closed set of $Y$. We have $X \backslash F^{-}(K)=F^{+}(Y \backslash K) \in \omega O(X)$; hence 
$\mathrm{F}^{-}(\mathrm{K}) \in \omega \mathrm{C}(\mathrm{X})$.

$(v) \Rightarrow(v i)$ : Let $B$ be any subset of $Y$. Since $\omega \mathrm{Cl}(\mathrm{B})$ is $\omega$-closed in $Y, \mathrm{~F}^{-}(\omega \mathrm{Cl}(\mathrm{B}))$ is $\omega$-closed in $X$ and $\mathrm{F}^{-}(\mathrm{B}) \subset \mathrm{F}^{-}(\omega \mathrm{Cl}(\mathrm{B}))$. Therefore, we obtain $\omega \mathrm{Cl}\left(\mathrm{F}^{-}(\mathrm{B})\right) \subset \mathrm{F}^{-}(\omega \mathrm{Cl}(\mathrm{B}))$.

$(v i) \Rightarrow(i)$ : Let $x \in X$ and $V \in \omega O(Y)$ with $F(x) \subset V$. Then we have $F(x) \cap(Y \backslash V)=\emptyset$; hence $x \notin \mathrm{F}^{-}(Y \backslash V)$. By $(v i), x \in \omega \mathrm{Cl}\left(\mathrm{F}^{-}(Y \backslash V)\right)$ and there exists $\mathrm{U} \in \omega \mathrm{O}(X, x)$ such that $\mathrm{U} \cap \mathrm{F}^{-}(\mathrm{Y} \backslash \mathrm{V})=\emptyset$. Therefore, we obtain $\mathrm{F}(\mathrm{U}) \subset \mathrm{V}$ and hence $\mathrm{F}$ is $u . \omega-i$.

Theorem 3.4. The following statements are equivalent for a multifunction $\mathrm{F}:(\mathrm{X}, \tau) \rightarrow(\mathrm{Y}, \sigma)$ :

(i) F is l.w-i.;

(ii) For each $\mathrm{V} \in \omega \mathrm{O}(\mathrm{Y})$ and each $\mathrm{x} \in \mathrm{F}^{-}(\mathrm{V})$, there exists $\mathrm{U} \in \mathrm{\omega O}(\mathrm{X}, \mathrm{x})$ such that $\mathrm{U} \subset \mathrm{F}^{-}(\mathrm{V})$;

(iii) $\mathrm{F}^{-}(\mathrm{V}) \in \omega \mathrm{O}(\mathrm{X})$ for every $\mathrm{V} \in \omega \mathrm{O}(\mathrm{Y})$;

(iv) $\mathrm{F}^{+}(\mathrm{K}) \in \omega \mathrm{C}(\mathrm{X})$ for every $\mathrm{K} \in \omega \mathrm{C}(\mathrm{Y})$;

(v) $\mathrm{F}(\omega \mathrm{Cl}(\mathrm{A})) \subset \omega \mathrm{Cl}(\mathrm{F}(\mathrm{A}))$ for every subset $\mathrm{A}$ of $\mathrm{X}$;

(vi) $\omega \mathrm{Cl}\left(\mathrm{F}^{+}(\mathrm{B})\right) \subset \mathrm{F}^{+}(\omega \mathrm{Cl}(\mathrm{B}))$ for every subset $\mathrm{B}$ of $\mathrm{Y}$.

Proof. $(\mathfrak{i}) \Rightarrow$ (ii): This is obvious.

$(\mathrm{ii}) \Rightarrow(\mathrm{iii})$ : Let $\mathrm{V} \in \omega \mathrm{\omega}(\mathrm{Y})$ and $x \in \mathrm{F}^{-}(\mathrm{V})$. There exists $\mathrm{U} \in \omega \mathrm{O}(\mathrm{X}, \mathrm{x})$ such that $\mathrm{U} \subset \mathrm{F}^{-}(\mathrm{V})$. Therefore, we have $\left.x \in \mathrm{U} \subset \mathrm{Cl}(\operatorname{int}(\mathrm{U})) \cup \operatorname{int}(\mathrm{Cl}(\mathrm{U})) \subset \mathrm{Cl}\left(\operatorname{int}\left(\mathrm{F}^{-}(\mathrm{V})\right)\right) \cup \operatorname{int}\left(\mathrm{Cl}_{\left(\mathrm{F}^{-}\right.}(\mathrm{V})\right)\right)$; hence $\mathrm{F}^{-}(\mathrm{V}) \in \omega \mathrm{O}(\mathrm{X})$.

(iii) $\Rightarrow(\mathfrak{i v})$ : Let $K$ be an $\omega$-closed set of $Y$. We have $X \backslash F^{+}(K)=F^{-}(Y \backslash K) \in \omega O(X)$; hence $\mathrm{F}^{+}(\mathrm{K}) \in \omega \mathrm{C}(\mathrm{X})$.

$(\mathfrak{i v}) \Rightarrow(v)$ and $(v) \Rightarrow(v i)$ : Straightforward.

$(v i) \Rightarrow(i)$ : Let $x \in X$ and $V \in \omega O(Y)$ with $F(x) \cap V \neq \emptyset$. Then $F(x)$ is not a subset of $Y \backslash V$ and $x \notin F^{+}(Y \backslash V)$. Since $Y \backslash V$ is $\omega$-closed in $Y$, by $(v i), x \notin \omega \operatorname{Cl}\left(F^{+}(Y \backslash V)\right)$ and there exists $\mathrm{U} \in \omega \mathrm{O}(\mathrm{X}, \mathrm{x})$ such that $\emptyset=\mathrm{U} \cap \mathrm{F}^{-}(\mathrm{Y} \backslash \mathrm{V})=\mathrm{U} \cap\left(\mathrm{X} \backslash \mathrm{F}^{-}(\mathrm{V})\right)$. Therefore, we obtain $\mathrm{U} \subset \mathrm{F}^{-}(\mathrm{V})$; hence $F$ is $l . \omega-i$..

Lemma 3.5. If $\mathrm{F}:(\mathrm{X}, \tau) \rightarrow(\mathrm{Y}, \sigma)$ is a multifunction, then $(\omega \mathrm{Cl} \mathrm{F})^{-}(\mathrm{V})=\mathrm{F}^{-}(\mathrm{V})$ for each $\mathrm{V} \in$ $\omega \mathrm{O}(\mathrm{Y})$.

Proof. Let $V \in \omega O(Y)$ and $x \in(\omega \mathrm{ClF})^{-}(\mathrm{V})$. Then $\mathrm{V} \cap(\omega \mathrm{Cl} F)(x) \neq \emptyset$. Since $V \in \omega O(Y)$, we have $\mathrm{V} \cap \mathrm{F}(\mathrm{x}) \neq \emptyset$ and hence $\mathrm{x} \in \mathrm{F}^{-}(\mathrm{V})$. Conversely, let $\mathrm{x} \in \mathrm{F}^{-}(\mathrm{V})$. Then $\emptyset \neq \mathrm{F}(\mathrm{x}) \cap \mathrm{V} \subset(\omega \mathrm{Cl} \mathrm{F})(\mathrm{x}) \cap \mathrm{V}$ and hence $x \in(\omega \mathrm{Cl} F)^{-}(V)$. Therefore, we obtain $(\omega \mathrm{Cl} F)^{-}(V)=\mathrm{F}^{-}(\mathrm{V})$.

Theorem 3.6. A multifunction $\mathrm{F}:(\mathrm{X}, \tau) \rightarrow(\mathrm{Y}, \sigma)$ is $\mathrm{l} . \omega$-i. if and only if $\omega \mathrm{ClF}:(\mathrm{X}, \tau) \rightarrow(\mathrm{Y}, \sigma)$ is l.w-i.

Proof. The proof is an immediate consequence of Lemma 3.5 and Theorem 3.4 (iii). 
Definition 3.7. A subset $\mathrm{A}$ of a topological space $(\mathrm{X}, \tau)$ is said to be:

(i) $\alpha$-regular [8] (resp. $\alpha$-w-regular) if for each $\mathrm{a} \in \mathrm{A}$ and any open (resp. $\boldsymbol{\omega}$-open) set $\mathrm{U}$ containing $\mathrm{a}$, there exists an open set $\mathrm{G}$ of $\mathrm{X}$ such that $\mathrm{a} \in \mathrm{G} \subset \mathrm{Cl}(\mathrm{G}) \subset \mathrm{U}$;

(ii) $\alpha$-paracompact [8] if every $\mathrm{X}$-open cover $\mathrm{A}$ has an $\mathrm{X}$-open refinement which covers $\mathrm{A}$ and is locally finite for each point of $\mathrm{X}$.

Lemma 3.8. If $\mathrm{A}$ is an $\alpha$ - $\omega$-regular, $\alpha$-paracompact subset of a space $\mathrm{X}$ and $\mathrm{U}$ is $\omega$-neighborhood of $\mathrm{A}$, then there exists an open set $\mathrm{G}$ of $\mathrm{X}$ such that $\mathrm{A} \subset \mathrm{G} \subset \mathrm{Cl}(\mathrm{G}) \subset \mathrm{U}$.

Proof. The proof is similar to that [8, Theorem 2.5].

Definition 3.9. A multifunction $\mathrm{F}:(\mathrm{X}, \tau) \rightarrow(\mathrm{Y}, \sigma)$ is said to be punctually $\alpha$-paracompact (resp. punctually $\alpha$ - $\omega$-regular, punctually $\alpha$-regular) if for each $\mathrm{x} \in \mathrm{X}, \mathrm{F}(\mathrm{x})$ is $\alpha$-paracompact (resp. $\alpha$ - $\omega$-regular, $\alpha$-regular $)$.

Lemma 3.10. If $\mathrm{F}:(\mathrm{X}, \tau) \rightarrow(\mathrm{Y}, \sigma)$ is punctually $\alpha$-paracompact and punctually $\alpha$ - $\omega$-regular, $(\omega \mathrm{Cl} F)^{+}(\mathrm{V})=\mathrm{F}^{+}(\mathrm{V})$ for each $\mathrm{V} \in \omega \mathrm{O}(\mathrm{Y})$.

Proof. Let $\mathrm{V} \in \omega \mathrm{O}(\mathrm{Y})$. Suppose that $x \in(\omega \mathrm{ClF})^{+}(\mathrm{V})$. Then, we have $\mathrm{F}(\mathrm{x}) \subset \omega \mathrm{Cl}(\mathrm{F}(\mathrm{x})) \subset \mathrm{V}$ and hence $x \in F^{+}(V)$. Therefore, we obtain $(\omega \mathrm{ClF})^{+}(V) \subset \mathrm{F}^{+}(\mathrm{V})$. Conversely, suppose that $x \in \mathrm{F}^{+}(\mathrm{V})$. Then $\mathrm{F}(\mathrm{x}) \subset \mathrm{V}$ and by Lemma 3.8 we have $\mathrm{F}(\mathrm{x}) \subset \mathrm{G} \subset \mathrm{Cl}(\mathrm{G}) \subset \mathrm{V}$ for some open set $G$ of $Y$. Therefore, $(\omega \mathrm{ClF})(x) \subset V$ and hence $x \in(\omega \mathrm{ClF})^{+}(\mathrm{V})$. Thus, we obtain $\mathrm{F}^{+}(\mathrm{V}) \subset(\omega \mathrm{ClF})^{+}(\mathrm{V})$; hence $(\omega \mathrm{ClF})^{+}(\mathrm{V})=\mathrm{F}^{+}(\mathrm{V})$.

Theorem 3.11. Let $\mathrm{F}:(\mathrm{X}, \tau) \rightarrow(\mathrm{Y}, \sigma)$ be punctually $\alpha$-paracompact and punctually $\alpha$ - $\omega$-regular multifunction. Then $\mathrm{F}$ is $\boldsymbol{u} . \boldsymbol{\omega}-\mathrm{i}$. if and only if $\omega \mathrm{Cl} \mathrm{F}:(\mathrm{X}, \tau) \rightarrow(\mathrm{Y}, \sigma)$ is $\boldsymbol{u} . \boldsymbol{\omega}-\mathrm{i}$..

Proof. The proof follows from Lemma 3.10 .

Lemma 3.12. [1] Let $\mathrm{A}$ and $\mathrm{B}$ be subsets of a topological space $(\mathrm{X}, \tau)$.

(i) If $\mathrm{A} \in \omega \mathrm{O}(\mathrm{X})$ and $\mathrm{B} \in \tau$, then $\mathrm{A} \cap \mathrm{B} \in \omega \mathrm{O}(\mathrm{B})$;

(ii) If $\mathrm{A} \in \omega \mathrm{O}(\mathrm{B})$ and $\mathrm{B} \in \omega \mathrm{O}(\mathrm{X})$, then $\mathrm{A} \in \omega \mathrm{O}(\mathrm{X})$.

Theorem 3.13. Let $\mathrm{F}:(\mathrm{X}, \tau) \rightarrow(\mathrm{Y}, \sigma)$ be a multifunction and $\mathrm{U}$ an open subset of $\mathrm{X}$. If $\mathrm{F}$ is a u.w-i. (resp. l.w-i.), then $\mathrm{F}_{\mid \mathrm{u}}: \mathrm{U} \rightarrow \mathrm{Y}$ is an $\mathrm{u} . \boldsymbol{\omega}$-i. (resp. l.w-i.).

Proof. Let $\mathrm{V}$ be any $\omega$-open set of $Y$. Let $x \in U$ and $x \in F_{l u}^{-}(V)$. Since $F$ is l.w-i. multifunction, then there exists an $\omega$-open set $G$ containing $x$ such that $G \subset F^{-}(V)$. Then $x \in G \cap U \in \omega O(U)$ and $\mathrm{G} \cap \mathrm{U} \subset \mathrm{F}_{\mathrm{lu}}^{-}(\mathrm{V})$. This shows that $\mathrm{F}_{\mathrm{lu}}$ is a $l . \omega$-i..

The proof of the $u . \omega-i$. of $F_{\mid u}$ is similar. 
Theorem 3.14. Let $\left\{\mathrm{U}_{i}: i \in \Delta\right\}$ be an open cover of a space $\mathrm{X}$. A multifunction $\mathrm{F}:(\mathrm{X}, \tau) \rightarrow(\mathrm{Y}, \sigma)$ is $\mathbf{u} . \omega-i$. if and only if the restriction $\mathrm{F}_{\mid \mathrm{u}_{i}}: \mathrm{U}_{i} \rightarrow \mathrm{Y}$ is $\mathbf{u} . \omega-\boldsymbol{i}$. for each $\mathrm{i} \in \Delta$.

Proof. Suppose that $F$ is $u$. $\omega$-i.. Let $i \in \Delta$ and $x \in U_{i}$ and $V$ be an $\omega$-open set of $Y$ containing $F_{\mid U_{i}}(x)$. Since $F$ is $u . \omega$-i. and $F(x)=F_{\mid U_{i}}(x)$, there exists $G \in \omega O(X, x)$ such that $F(G) \subset V$. Set $\mathrm{U}=\mathrm{G} \cap \mathrm{U}_{i}$, then $x \in \mathrm{U} \in \omega \mathrm{O}\left(\mathrm{U}_{i}, x\right)$ and $\mathrm{F}_{\mid \mathrm{U}_{i}}(\mathrm{U})=\mathrm{F}(\mathrm{U}) \subset \mathrm{V}$. Therefore, $\mathrm{F}_{\mid \mathrm{U}_{i}}$ is $u$.w$i$..Conversely, let $x \in X$ and $V \in \omega O(Y)$ containing $F(x)$. There exists $i \in \Delta$ such that $x \in U_{i}$. Since $F_{\mid U_{i}}$ is $u . \omega$-i. and $F(x)=F_{\mid U_{i}}(x)$, there exists $U \in \omega O\left(U_{i}, x\right)$ such that $F_{\mid U_{i}}(U) \subset V$. Then we have $U \in \omega O(X, x)$ and $F(U) \subset V$. Therefore, $F$ is $u . \omega-i$..

Theorem 3.15. Let $\left\{\mathrm{U}_{i}: i \in \Delta\right\}$ be an open cover of a space $\mathrm{X}$. A multifunction $\mathrm{F}:(\mathrm{X}, \tau) \rightarrow(\mathrm{Y}, \sigma)$ is l.w-i. if and only if the restriction $\mathrm{F}_{\mid \mathrm{U}_{i}}: \mathrm{U}_{i} \rightarrow \mathrm{Y}$ is l.w-i. for each $\mathrm{i} \in \Delta$.

Proof. The proof is similar to that of Theorem 3.14 and is thus omitted.

Definition 3.16. A subset $\mathrm{K}$ of a space $\mathrm{X}$ is said to be $\mathrm{\omega}$-compact relative to $\mathrm{X}$ [Q] (resp. $\omega$ Lindelöf relative to $\mathrm{X}[9]$ ) if every cover of $\mathrm{K}$ by $\omega$-open sets of $\mathrm{X}$ has a finite (resp. countable) subcover. A space $\mathrm{X}$ is said to be $\omega$-compact [2] (resp. $\omega$-Lindelöf [9]) if $\mathrm{X}$ is $\omega$-compact (resp. $\omega$-Lindelöf) relative to $\mathrm{X}$.

Theorem 3.17. Let $\mathrm{F}:(\mathrm{X}, \tau) \rightarrow(\mathrm{Y}, \sigma)$ be an $\mathrm{u} . \mathrm{\omega}$-i. multifunction and $\mathrm{F}(\mathrm{x})$ is $\boldsymbol{\omega}$-compact relative to $\mathrm{Y}$ for each $\mathrm{x} \in \mathrm{X}$. If $\mathrm{A}$ is $\omega$-compact relative to $\mathrm{X}$, then $\mathrm{F}(\mathrm{A})$ is $\omega$-compact relative to $\mathrm{Y}$.

Proof. Let $\left\{V_{i}: i \in \Delta\right\}$ be any cover of $F(A)$ by $\omega$-open sets of $Y$. For each $x \in A$, there exists a finite subset $\Delta(x)$ of $\Delta$ such that $F(x) \subset \cup\left\{V_{i}: i \in \Delta(x)\right\}$. Put $V(x)=\cup\left\{V_{i}: i \in \Delta(x)\right\}$. Then $\mathrm{F}(\mathrm{x}) \subset \mathrm{V}(\mathrm{x}) \in \omega \mathrm{O}(\mathrm{Y})$ and there exists $\mathrm{U}(\mathrm{x}) \in \omega \mathrm{O}(\mathrm{X}, \mathrm{x})$ such that $\mathrm{F}(\mathrm{U}(\mathrm{x})) \subset \mathrm{V}(\mathrm{x})$. Since $\{U(x): x \in A\}$ is an $\omega$-open cover of $A$, there exists a finite number of points of $A$, say, $x_{1}, x_{2}, \ldots . x_{n}$ such that $A \subset \cup\left\{U\left(x_{i}\right): i=1,2, \ldots . n\right\}$. Therefore, we obtain $F(A) \subset F\left(\bigcup_{i=1}^{n} U\left(x_{i}\right)\right) \subset \bigcup_{i=1}^{n} F\left(U\left(x_{i}\right)\right) \subset$ $\bigcup_{i=1}^{n} V\left(x_{i}\right) \subset \bigcup_{i=1}^{n} \underset{i \in \Delta\left(x_{i}\right)}{\cup} V_{i}$. This shows that $F(A)$ is $\omega$-compact relative to $Y$.

Corollary 3.18. Let $\mathrm{F}:(\mathrm{X}, \tau) \rightarrow(\mathrm{Y}, \sigma)$ be an $\mathrm{u} . \mathrm{\omega}-\mathrm{i}$. surjective multifunction and $\mathrm{F}(\mathrm{x})$ is $\boldsymbol{\omega}$ compact relative to $\mathrm{Y}$ for each $\mathrm{x} \in \mathrm{X}$. If $\mathrm{X}$ is $\boldsymbol{\omega}$-compact, then $\mathrm{Y}$ is $\boldsymbol{\omega}$-compact.

Theorem 3.19. Let $\mathrm{F}:(\mathrm{X}, \tau) \rightarrow(\mathrm{Y}, \sigma)$ be an $\mathrm{u} . \mathrm{\omega}$-i. multifunction and $\mathrm{F}(\mathrm{x})$ is $\omega$-Lindelöf relative to $\mathrm{Y}$ for each $\mathrm{x} \in \mathrm{X}$. If $\mathrm{A}$ is $\mathrm{\omega}$-Lindelöf relative to $\mathrm{X}$, then $\mathrm{F}(\mathrm{A})$ is $\omega$-Lindelöf relative to $\mathrm{Y}$.

Proof. The proof is similar to that of Theorem 3.17 and is thus omitted.

Corollary 3.20. Let $\mathrm{F}:(\mathrm{X}, \tau) \rightarrow(\mathrm{Y}, \sigma)$ be an $\mathrm{u} . \boldsymbol{\omega}$-i. surjective multifunction and $\mathrm{F}(\mathrm{x})$ is $\boldsymbol{\omega}$ Lindelöf relative to $\mathrm{Y}$ for each $\mathrm{x} \in \mathrm{X}$. If $\mathrm{X}$ is $\mathrm{\omega}$-Lindelöf, then $\mathrm{Y}$ is $\mathrm{\omega}$-Lindelöf.

Definition 3.21. A topological space $\mathrm{X}$ is said to be $\omega$-normal [10] if for any pair of disjoint closed subsets $\mathrm{A}, \mathrm{B}$ of $\mathrm{X}$, there exist disjoint $\mathrm{U}, \mathrm{V} \in \omega \mathrm{O}(\mathrm{X})$ such that $\mathrm{A} \subset \mathrm{U}$ and $\mathrm{B} \subset \mathrm{V}$. 
Theorem 3.22. If $Y$ is $\omega$-normal and $\mathrm{F}_{i}: X_{i} \rightarrow Y$ is an $u . \omega-i$. multifunction such that $\mathrm{F}_{i}$ is punctually closed for $\mathfrak{i}=1,2$ and the product of two $\boldsymbol{\omega}$-open sets is $\boldsymbol{\omega}$-open, then the set $\left\{\left(\mathrm{x}_{1}, \mathrm{x}_{2}\right) \in \mathrm{X}_{1} \times \mathrm{X}_{2}: \mathrm{F}_{1}\left(\mathrm{x}_{1}\right) \cap \mathrm{F}_{2}\left(\mathrm{x}_{2}\right) \neq \emptyset\right\}$ is $\omega$-closed in $\mathrm{X}_{1} \times \mathrm{X}_{2}$.

Proof. Let $A=\left\{\left(x_{1}, x_{2}\right) \in X_{1} \times X_{2}: F_{1}\left(x_{1}\right) \cap F_{2}\left(x_{2}\right) \neq \emptyset\right\}$ and $\left(x_{1}, x_{2}\right) \in\left(X_{1} \times X_{2}\right) \backslash A$. Then $F_{1}\left(x_{1}\right) \cap F_{2}\left(x_{2}\right)=\emptyset$. Since $Y$ is $\omega$-normal and $F_{i}$ is punctually closed for $i=1,2$, there exist disjoint $V_{1}, V_{2} \in \omega O(X)$ such that $F_{i}\left(x_{i}\right) \subset V_{i}$ for $i=1$, 2. Since $F_{i}$ is $u . \omega-i$., $F_{i}^{+}\left(V_{i}\right) \in \omega O\left(X_{i}, x_{i}\right)$ for $i=1,2$. Put $U=F_{1}^{+}\left(V_{1}\right) \times F_{2}^{+}\left(V_{2}\right)$, then $U \in \omega O\left(X_{1} \times X_{2}\right)$ and $\left(x_{1}, x_{2}\right) \in U \subset\left(X_{1} \times X_{2}\right) \backslash A$. This shows that $\left(X_{1} \times X_{2}\right) \backslash A \in \omega O\left(X_{1} \times X_{2}\right)$; hence $A$ is $\omega$-closed set in $X_{1} \times X_{2}$.

Definition 3.23. [2] Let $\mathrm{A}$ be a subset of a topological space $\mathrm{X}$. The $\boldsymbol{\omega}$-frontier of $\mathrm{A}$ denoted by $\omega \operatorname{Fr}(A)$, is defined as follows: $\omega \operatorname{Fr}(A)=\omega \operatorname{Cl}(A) \cap \omega \operatorname{Cl}(X \backslash A)$.

Theorem 3.24. The set of a point $x$ of $X$ at which a multifunction $F:(X, \tau) \rightarrow(Y, \sigma)$ is not u.w-i. (resp. l.w-i.) is identical with the union of the $\omega$-frontiers of the upper (resp. lower) inverse images of $\omega$-open sets containing (resp. meeting) $\mathrm{F}(\mathrm{x})$.

Proof. Let $x$ be a point of $X$ at which $F$ is not $u . \omega$-i.. Then there exists $V \in \omega O(Y)$ containing $F(x)$ such that $\mathrm{U} \cap\left(X \backslash F^{+}(V)\right) \neq \emptyset$ for each $\mathrm{U} \in \omega \mathrm{O}(X, x)$. Then $x \in \omega \operatorname{Cl}\left(X \backslash F^{+}(V)\right)$. Since $x \in F^{+}(V)$, we have $x \in \omega \mathrm{Cl}\left(\mathrm{F}^{+}(Y)\right.$ and hence $x \in \omega \mathrm{Fr}\left(\mathrm{F}^{+}(A)\right)$. Conversely, let $V \in \omega O(Y)$ containing $\mathrm{F}(x)$ and $x \in \omega \operatorname{Fr}\left(F^{+}(V)\right)$. Now, assume that $F$ is $u . \omega$-i. at $x$, then there exists $U \in \omega O(X, x)$ such that $\mathrm{F}(\mathrm{U}) \subset \mathrm{V}$. Therefore, we obtain $x \in \mathrm{U} \subset \omega \operatorname{int}\left(\mathrm{F}^{+}(\mathrm{V})\right.$. This contradicts that $x \in \omega \mathrm{Fr}\left(\mathrm{F}^{+}(\mathrm{V})\right)$. Thus, $F$ is not $\boldsymbol{u} . \boldsymbol{\omega}$-i.. The proof of the second case is similar.

For a multifunction $F:(X, \tau) \rightarrow(Y, \sigma)$, the graph multifunction $G_{F}(x): X \rightarrow X \times Y$ is defined as follows: $\mathrm{G}_{\mathrm{F}}(\mathrm{x})=\{x\} \times \mathrm{F}(\mathrm{x})$ for all $\mathrm{x} \in \mathrm{X}$.

Lemma 3.25. For a multifunction $\mathrm{F}:(\mathrm{X}, \tau) \rightarrow(\mathrm{Y}, \sigma)$, the following holds:

(i) $\mathrm{G}_{\mathrm{F}}^{+}(\mathrm{A} \times \mathrm{B})=\mathrm{A} \cap \mathrm{F}^{+}(\mathrm{B})$;

(ii) $\mathrm{G}_{\mathrm{F}}^{-}(\mathrm{A} \times \mathrm{B})=\mathrm{A} \cap \mathrm{F}^{-}(\mathrm{B})$

for any subset $\mathrm{A}$ of $\mathrm{X}$ and $\mathrm{B}$ of $\mathrm{Y}$.

Theorem 3.26. Let $\mathrm{F}:(\mathrm{X}, \tau) \rightarrow(\mathrm{Y}, \sigma)$ be a multifunction and $\mathrm{X}$ be a connected space. If the graph multifunction of $\mathrm{F}$ is u.w-i. (respectively l.w-i.), then $\mathrm{F}$ is u.w-i. (respectively. l.w-i.).

Proof. Let $x \in X$ and $V$ be any $\omega$-open subset of $Y$ containing $F(x)$. Since $X \times V$ is an $\omega$-open set of $X \times Y$ and $G_{F}(x) \subset X \times V$, there exists an $\omega$-open set $U$ containing $x$ such that $G_{F}(U) \subset X \times V$. By Lemma 3.25 we have $\mathrm{U} \subset \mathrm{G}_{\mathrm{F}}^{+}(\mathrm{X} \times \mathrm{V})=\mathrm{F}^{+}(\mathrm{V})$ and $\mathrm{F}(\mathrm{U}) \subset \mathrm{V}$. Thus, $\mathrm{F}$ is $\mathrm{u}$. $\boldsymbol{\omega}$-i.. The proof of the l.w-i. of $\mathrm{F}$ can be obtained in a similar manner. 
Definition 3.27. [2] A topological space $(\mathrm{X}, \tau)$ is said to $\omega-\mathrm{T}_{2}$ if for each pair of distinct points $\mathrm{x}$ and $\mathrm{y}$ in $\mathrm{X}$, there exist disjoint $\mathrm{\omega}$-open sets $\mathrm{U}$ and $\mathrm{V}$ in $\mathrm{X}$ such that $\mathrm{x} \in \mathrm{U}$ and $\mathrm{y} \in \mathrm{V}$.

Theorem 3.28. If $\mathrm{F}:(\mathrm{X}, \tau) \rightarrow(\mathrm{Y}, \sigma)$ is an $\mathrm{u} . \boldsymbol{\omega}$-i. injective multifunction and point closed from a topological space $\mathrm{X}$ to an $\mathrm{\omega}$-normal space $\mathrm{Y}$, then $\mathrm{X}$ is an $\mathrm{\omega}-\mathrm{T}_{2}$ space.

Proof. Let $x$ and $y$ be any two distinct points in $X$. Then we have $F(x) \cap F(y)=\varnothing$ since $F$ is injective. Since $\mathrm{Y}$ is $\omega$-normal, it follows that there exist disjoint open sets $\mathrm{U}$ and $\mathrm{V}$ containing $F(x)$ and $F(y)$, respectively. Thus, there exist disjoint $\omega$-open sets $F^{+}(U)$ and $F^{+}(V)$ containing $x$ and $y$, respectively such $G \subset F^{+}(U)$ and $W \subset F^{+}(V)$. Therefore, we obtain $G \cap W=\emptyset$; hence $X$ is $\omega-T_{2}$.

Definition 3.29. A multifunction $\mathrm{F}:(\mathrm{X}, \tau) \rightarrow(\mathrm{Y}, \sigma)$ is said have an $\omega$-closed graph if for each pair $(\mathrm{x}, \mathrm{y}) \notin \mathrm{G}(\mathrm{F})$ there exist $\mathrm{U} \in \omega \mathrm{O}(\mathrm{X}, \mathrm{x})$ and $\mathrm{V} \in \omega \mathrm{O}(\mathrm{Y}, \mathrm{y})$ such that $(\mathrm{U} \times \mathrm{V}) \cap \mathrm{G}(\mathrm{F})=\emptyset$.

Theorem 3.30. Let $\mathrm{F}:(\mathrm{X}, \tau) \rightarrow(\mathrm{Y}, \sigma)$ be an $\mathrm{u} . \omega$-c. multifunction. If $\mathrm{F}(\mathrm{x})$ is $\alpha$-paracompact for each $\mathrm{x} \in \mathrm{X}$, then $\mathrm{G}(\mathrm{F})$ is $\omega$-closed.

Proof. Suppose that $\left(x_{0}, y_{0}\right) \notin G(F)$. Then $y_{0} \notin F\left(x_{0}\right)$. Since $Y$ is a $T_{2}$ space, for each $y \in$ $F\left(x_{0}\right)$ there exist disjoint open sets $V(y)$ and $W(y)$ containing $y$ and $y_{0}$, respectively. The family $\left\{\mathrm{V}(\mathrm{y}): y \in F\left(x_{0}\right)\right\}$ is an open cover of $F\left(x_{0}\right)$. Thus, by $\alpha$-paracompactness of $F\left(x_{0}\right)$, there is a locally finite open cover $\Delta=\left\{\mathrm{U}_{\beta}: \beta \in \mathrm{I}\right\}$ which refines $\left\{\mathrm{V}(\mathrm{y}): \mathrm{y} \in \mathrm{F}\left(\mathrm{x}_{0}\right)\right\}$. Therefore, there exists an open neighborhood $W_{0}$ of $y_{0}$ such that $W_{0}$ intersects only finitely many members $U_{\beta_{1}}$, $\mathrm{U}_{\beta_{2}}, \ldots . . . \mathrm{U}_{\beta_{n}}$ of $\Delta$. Choose $y_{1}, y_{2}, \ldots . . y_{n}$ in $F\left(x_{0}\right)$ such that $U_{\beta_{i}} \subset V\left(y_{i}\right)$ for each $1 \leq i \leq n$, and set $W=W_{0} \cap\left(\bigcap_{i=1}^{n} W\left(y_{i}\right)\right)$. Then $W$ is an open neighborhood of $y_{0}$ such that $W \cap\left(\underset{\beta \in I}{\cup} V_{\beta}\right)=\emptyset$. By the upper $\omega$-continuity of $F$, there is a $U \in \omega O\left(X, x_{0}\right)$ such that $U \subset F^{+}\left(\underset{\beta \in I}{\cup} V_{\beta}\right)$. It follows that $(\mathrm{U} \times \mathrm{W}) \cap \mathrm{G}(\mathrm{F})=\emptyset$. Therefore, $\mathrm{G}(\mathrm{F})$ is $\omega$-closed.

Theorem 3.31. Let $\mathrm{F}:(\mathrm{X}, \tau) \rightarrow(\mathrm{Y}, \sigma)$ be a multifunction from a space $\mathrm{X}$ into an $\mathrm{\omega}$-compact space $\mathrm{Y}$. If $\mathrm{G}(\mathrm{F})$ is $\boldsymbol{\omega}$-closed, then $\mathrm{F}$ is u.w-c..

Proof. Suppose that $\mathrm{F}$ is not $\mathrm{u} . \boldsymbol{\omega}$-c.. Then there exists a nonempty closed subset $\mathrm{C}$ of $\mathrm{Y}$ such that $\mathrm{F}^{-}(\mathrm{C})$ is not $\omega$-closed in $\mathrm{X}$. We may assume that $\mathrm{F}^{-}(\mathrm{C}) \neq \emptyset$. Then there exists a point $x_{0} \in \omega \mathrm{Cl}\left(F^{-}(C)\right) \backslash F^{-}(C)$. Hence for each point $y \in C$, we have $\left(x_{0}, y\right) \notin G(F)$. Since $F$ has an $\omega$-closed graph, there are $\omega$-open subsets $\mathrm{U}(\mathrm{y})$ and $\mathrm{V}(\mathrm{y})$ containing $\mathrm{x}_{0}$ and $y$, respectively such that $(\mathrm{U}(\mathrm{y}) \times \mathrm{V}(\mathrm{y})) \cap \mathrm{G}(\mathrm{F})=\emptyset$. Then $\{\mathrm{Y} \backslash \mathrm{C}\} \cup\{\mathrm{V}(\mathrm{y}): \mathrm{y} \in \mathrm{C}\}$ is an $\boldsymbol{w}$-open cover of $\mathrm{Y}$, and thus it has a subcover $\{Y \backslash C\} \cup\left\{V\left(y_{i}\right): y_{i} \in C, 1 \leq i \leq n\right\}$. Let $U=\bigcap_{i=1}^{n} U\left(y_{i}\right)$ and $V=\bigcup_{i=1}^{n} V\left(y_{i}\right)$. It is easy to verify that $C \subset V$ and $(U \times V) \cap G(F)=\emptyset$. Since $U$ is an $\omega$-neighborhood of $x_{0}, U_{\cap} \cap F^{-}(C) \neq \emptyset$. It follows that $\emptyset \neq(\mathrm{U} \times \mathrm{C}) \cap \mathrm{G}(\mathrm{F}) \subset(\mathrm{U} \times \mathrm{V}) \cap \mathrm{G}(\mathrm{F})$. This is a contradiction. Hence the proof is completed.

Corollary 3.32. Let $\mathrm{F}:(\mathrm{X}, \tau) \rightarrow(\mathrm{Y}, \sigma)$ be a multifunction into an $\omega$-compact $\mathrm{T}_{2}$ space $\mathrm{Y}$ such that $\mathrm{F}(\mathrm{x})$ is $\boldsymbol{\omega}$-closed for each $\mathrm{x} \in \mathrm{X}$. Then $\mathrm{F}$ is $\boldsymbol{u} . \boldsymbol{\omega}$-c. if and only if it has an $\boldsymbol{\omega}$-closed graph. 
Theorem 3.33. Let $\mathrm{F}:(\mathrm{X}, \tau) \rightarrow(\mathrm{Y}, \sigma)$ be an $\mathrm{u} . \mathrm{\omega}-\mathrm{i}$. multifunction into an $\mathrm{\omega}-\mathrm{T}_{2}$ space $\mathrm{Y}$. If $\mathrm{F}(\mathrm{x})$ is $\alpha$-paracompact for each $\mathrm{\chi} \in \mathrm{X}$, then $\mathrm{G}(\mathrm{F})$ is $\omega$-closed.

Proof. The proof is clear.

Definition 3.34. [14 Let $\mathrm{A}$ be a subset of $\mathrm{X}$. Then $\mathrm{F}: \mathrm{X} \rightarrow \mathrm{A}$ is called a retracting multifunction if $\mathrm{x} \in \mathrm{F}(\mathrm{x})$ for each $\mathrm{x} \in \mathrm{A}$.

Theorem 3.35. Let $\mathrm{F}: \mathrm{X} \rightarrow \mathrm{X}$ be an $\mathrm{u} . \mathrm{\omega}$-i. multifunction of a $\mathrm{T}_{2}$ space $\mathrm{X}$ into itself. If $\mathrm{F}(\mathrm{x})$ is $\alpha$-paracompact for each $\mathrm{x} \in \mathrm{X}$, then the set $\mathrm{A}=\{\mathrm{x}: \mathrm{x} \in \mathrm{F}(\mathrm{x})\}$ is $\omega$-closed.

Proof. Let $x_{0} \in \omega \operatorname{Cl}(A) \backslash A$. Then $x_{0} \notin \mathrm{F}\left(x_{0}\right)$. Since $X$ is $T_{2}$, for each $x \in F\left(x_{0}\right)$ there exist disjoint open sets $\mathrm{U}(\mathrm{x})$ and $\mathrm{V}(\mathrm{x})$ containing $\mathrm{x}_{0}$ and $\mathrm{x}$ respectively. Then $\left\{\mathrm{V}(\mathrm{x}): \mathrm{x} \in \mathrm{F}\left(\mathrm{x}_{0}\right)\right\}$ is an open cover of $F\left(x_{0}\right)$. By the $\alpha$-paracompactness of $F\left(x_{0}\right),\left\{V(x): x \in F\left(x_{0}\right)\right\}$ has a locally finite open refinement $\mathcal{W}=\left\{W_{\beta}: \beta \in I\right\}$ which covers $F\left(x_{0}\right)$. Therefore, we can choose an open neighborhood $U_{0}$ of $x_{0}$ such that $U_{0}$ intersects only finitely many members $W_{\beta_{1}}, W_{\beta_{2}}, \ldots . . W_{\beta_{n}}$ of $\mathcal{W}$. Choose $x_{1}, x_{2}, \ldots . . x_{n}$ in $F\left(x_{0}\right)$ such that $W_{\beta_{i}} \subset V\left(x_{i}\right)$ for each $1 \leq i \leq n$, and set $U=U_{0} \cap\left(\bigcap_{i=1}^{n} U\left(x_{i}\right)\right)$. Then $U$ is an open neighborhood of $x_{0}$ such that $U \cap\left(\underset{\beta \in I}{\cup} W_{\beta}\right)=\emptyset$. Since $F$ is $u$. $w$-i., there is a $\mathrm{G} \in \omega \mathrm{O}\left(\mathrm{X}, x_{0}\right)$ such that $\mathrm{G} \subset \mathrm{F}^{+}\left(\underset{\beta \in \mathrm{I}}{\cup} \mathrm{W}_{\beta}\right)$. It follows that $\mathrm{G} \cap \mathrm{U}$ is an $\omega$-neighborhood of $x_{0}$ and satisfies $(G \cap U) \cap A=\emptyset$. This contradicts the fact that $x_{0} \in \omega \mathrm{Cl}(A)$.

Corollary 3.36. Let $\mathrm{A}$ be a subset of $\mathrm{X}$ and $\mathrm{F}: \mathrm{X} \rightarrow \mathrm{A}$ an $\mathrm{u} . \mathrm{\omega}-\mathrm{i}$. retracting multifunction such that $\mathrm{F}(\mathrm{x})$ is $\alpha$-paracompact for each $\mathrm{x} \in \mathrm{A}$. If $\mathrm{X}$ is $\mathrm{T}_{2}$, then $\mathrm{A}$ is $\omega$-closed.

Received: March 2014. Accepted: May 2014.

\section{References}

[1] K. Al-Zoubi and B. Al-Nashef, The topology of $\omega$-open subsets, Al-Manarah (9) (2003), 169179.

[2] A. Al-omari ans M. S. M. Noorani, Contra- $\omega$-continuous and almost $\omega$-continuous functions, Int. J. Math. Math. Sci. (9) (2007), 169-179.

[3] T. Banzaru, Multifunctions and M-product spaces, Bull. Stin. Tech. Inst. Politech. Timisoara, Ser. Mat. Fiz. Mer. Teor. Apl., 17(31)(1972), 17-23.

[4] C. Carpintero, N. Rajesh, E. Rosas and S. Saranyasri, Some properties of upper/lower wcontinuous multifunctions (submitted).

[5] C. Carpintero, N. Rajesh, E. Rosas and S. Saranyasri, On upper and lower faintly $\omega$-continuous multifunctions (submitted). 
[6] C. Carpintero, N. Rajesh, E. Rosas and S. Saranyasri, On Slightly omega-continuous multifunctions, to appear in Punjab University Journal of Mathematics (2014).

[7] C. Carpintero, N. Rajesh, E. Rosas and S. Saranyasri, Properties of Faintly w-continuous functions, Boletin de Matematicas, 20(2) (2014). 135-143.

[8] I. Kovacevic, Subsets and paracompactness, Univ. u. Novom Sadu, Zb. Rad. Prirod. Mat. Fac. Ser. Mat., 14(1984), 79-87.

[9] H. Z. Hdeib, w-closed mappings, Revista Colombiana Mat., 16(1982), 65-78.

[10] T. Noiri, A. Al-omari and M. S. M. Noorani, Slightly w-continuous functions, Fasc. Math., (41) (2009), 97-106.

[11] T. Noiri and V. Popa, Almost weakly continuous multifunctions, Demonstratio Math., 26 (1993), 363-380.

[12] T. Noiri and V. Popa, A unified theory of almost continuity for multifunctions, Sci. Stud. Res. Ser. Math. Inform., 20(1) (2010),185-214.

[13] T. Noiri and V. Popa, A unified theory of weak continuity for multifunctions, Stud. Cerc. St Ser. Mat. Univ. Bacau, 16 (2006),167-200.

[14] G. T. Whyburn, Retracting multifunctions, Proc. Nat. Acad. Sci., 59(1968), 343-348.

[15] I. Zorlutuna, w-continuous multifunctions, Filomat, 27(1) (2013), 155-162. 